2006-01-01

\title{
Optimising the rating of the UPQC for applying to the fault ride through enhancement of wind generation
}

\author{
N. G. Jayanti \\ Technological University Dublin \\ Malabika Basu \\ Technological University Dublin, mbasu@tudublin.ie \\ Michael Conlon \\ Technological University Dublin, michael.conlon@tudublin.ie
}

See next page for additional authors

Follow this and additional works at: https://arrow.tudublin.ie/engscheleart

Part of the Electrical and Computer Engineering Commons

\section{Recommended Citation}

Jayanti, N. G. :Optimising the rating of the UPQC for applying to the fault ride through enhancement of wind generation. UPEC, '06: Proceedings of the 41st International Universities Power Engineering Conference, Newcastle-Upon-Tyne, England, 6-8 September, 2006, vol. 1, pp.123-127. doi:10.21427/ 9pa1-v549

This Conference Paper is brought to you for free and open access by the School of Electrical and Electronic Engineering at ARROW@TU Dublin. It has been accepted for inclusion in Conference papers by an authorized administrator of ARROW@TU Dublin. For more information, please contact arrow.admin@tudublin.ie, aisling.coyne@tudublin.ie,gerard.connolly@tudublin.ie. Funder: Enterprise Ireland Technology Commercialisation Fund.

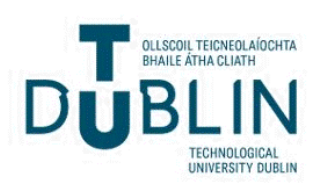




\section{Authors}

N. G. Jayanti, Malabika Basu, Michael Conlon, and Kevin Gaughan

This conference paper is available at ARROW@TU Dublin: https://arrow.tudublin.ie/engscheleart/106 


\title{
OPTIMISING THE RATING OF THE UPQC FOR APPLYING TO THE FAULT RIDE THROUGH ENHANCEMENT OF WIND GENERATION
}

\author{
N. G. Jayanti, Malabika Basu, Michael F. Conlon, Kevin Gaughan \\ Dublin Institute of Technology, Ireland
}

\begin{abstract}
The Unified Power Quality Conditioner (UPQC) is a combination of a shunt and a series compensator cascaded via a DC link capacitor which works on the combined principle of active filtering and dynamic voltage restoration. Therefore, the UPQC can be a potential solution to the grid integration problems associated with fixed speed wind generators including reactive power compensation and fault ride through capability. The hardware design of the UPQC can be made more cost effective by proper selection of the rating of the individual compensators of the UPQC. It is shown in the paper that the application of a fixed capacitor can lower the cost of the UPQC further, without compromising the performance. The fixed capacitor shares the reactive power load with the shunt compensator and the overall rating of the UPQC is reduced. The proposed scheme also helps in reducing the power loss occurring in the power electronic switches as current conduction of the switches is reduced. Simulation results are provided in the paper to support the theory.
\end{abstract}

Keywords: Unified Power Quality Conditioner, Wind Generation, Fault Ride Through

\section{Introduction}

The UPQC is a versatile power conditioning device which works on the combined principle of active filtering and dynamic voltage restoration. It finds its application in mitigating the power quality problems commonly occurring in electrical networks such as voltage sag/swell, voltage flicker, excessive reactive power demand and harmonics. The UPQC can be connected as an interface between the utility and the consumer as it can prevent power quality problems entering the network and also protects sensitive loads from the disturbances occurring in the network. It has been demonstrated that a UPQC stands as a potential solution to grid connecting issues of Fixed Speed Induction Generators (FSIG) driven by wind turbines [1]. The typical grid connecting issues in relation to a FSIG are reactive power compensation and fault ride through capability. The fault ride through capability of FSIG is greatly enhanced by the application of a UPQC. Also the reactive power requirement of the generator is taken care of by the UPQC. In [2] a realistic estimation of the rating of the UPQC required for this type of application has been investigated. A general principle has been suggested for deciding the optimum rating of the individual compensators of the UPQC in order to reduce the installation cost. In this work an attempt has been made to further optimise the rating of the UPQC by application of a fixed capacitor in order to share the reactive power requirement of the generator between these active and the passive compensating devices.

\section{Model Configuration and Simulation}

The system considered for simulation study and analysis is shown here in Figure 1. A FSIG driven by a wind turbine is connected to the grid through a double line transmission network. A UPQC is connected at the Point of Common Coupling (PCC).

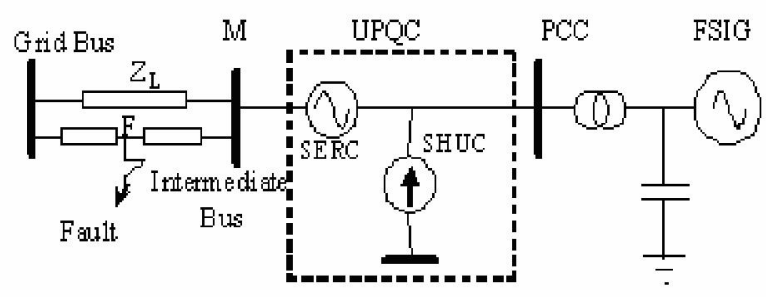

Figure 1 Model Configuration

A capacitor is connected at the generator terminals. The reactive power to be supplied to the generator is shared by the Shunt Compensator (SHUC) of the UPQC and the fixed capacitor. A three phase fault is created at the mid point of one of the buses, which is followed by a voltage sag at the generator terminals. The voltage sag results in reduced electromagnetic torque and reduced electrical power output. Due to the mismatch in the mechanical and electrical torque during the sag period, the generator starts accelerating [3]. This is accompanied by drawing a huge amount of reactive power from connecting power system, and the generator fails to return to its pre-sag terminal voltage 
if pull-out value of the slip is reached. Ultimately the machine will have to be disconnected from the rest of the power system. But the application of a UPQC ensures that voltage at the machine terminals remains at the level such that generator is capable of ride through the fault.

\subsection{Machine model}

The simulation model of a FSIG is a standard asynchronous machine block available in SimPowerSystem toolbox of MATLAB/Simulink. This machine can operate as a motor or a generator based on the convention of the mechanical torque. In the simulation model, the machine is driven by a wind turbine of $2 \mathrm{MW}$ capacity. The other parameters of the generator can be found in the Appendix A.

\section{$2.2 \quad$ Network Model}

The network is modelled with the standard RLC blocks available in the SimPowerSystem toolbox of MATLAB/Simulink. A double line weak network is considered here with a fault level of 16 MVA. Three phase balanced faults of varying severity are created at point $\mathrm{F}$ (midpoint of the line) in Figure 1, by creating short circuit to earth through different fault impedances. This initiates different sag levels at the PCC.

\subsection{UPQC Model}

The UPQC is modelled with the standard blocks available in MATLAB/Simulink. It is a combination of a shunt (SHUC) and a series (SERC) compensator cascaded via a DC link capacitor which facilitates the sharing of the active power between the two compensators. For the purpose of this paper the SHUC of the UPQC is modelled as a controlled current source and the SERC is modelled as a controlled voltage source. The structure of the model is represented in Figure 2[1].

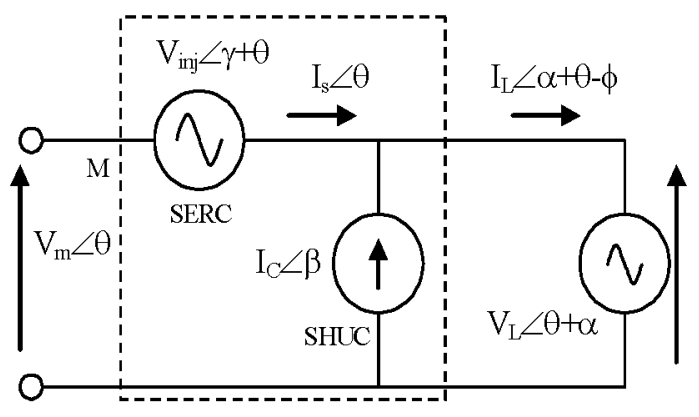

Figure 2. Fundamental frequency representation of the UPQC

The generator terminal voltage is represented as $V_{L}$. $I_{L}$ is the generator current. $V_{m}$ is the intermediate bus voltage and $\mathrm{V}_{\text {inj }}$ is the voltage injected by the SERC of the UPQC. Voltage is injected in phase with the machine terminal voltage in the case study considered here. $I_{S}$ is the grid current and $I_{C}$ is the current injected from the SHUC of the UPQC. The dynamics of the DC link capacitor is ignored in the modelling of the UPQC. This has been done on the assumption that the DC link capacitor voltage stays constant all the time.

The control objective to be achieved during the normal working condition is that the SHUC of the UPQC must provide the reactive power required by the generator, connecting transformer or any other inductive device. During any abnormal condition, the SERC of the UPQC should regulate the incoming voltage quality and compensate for any voltage sag or swell and the SHUC should continue to provide the reactive power and at the same time should maintain the DC link capacitor voltage at a constant value. The phasor diagrams corresponding to normal working condition and the abnormal condition are represented in Figure 3 and Figure 4. The suffixes 1 and 2 of the different current and voltage labels correspond to normal and fault conditions respectively

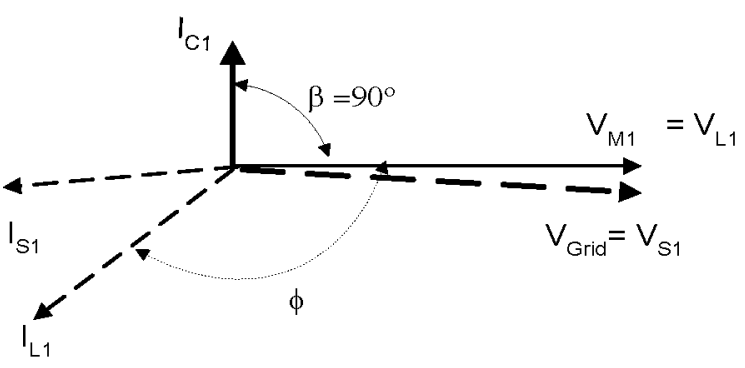

\section{Figure 3. Phasor diagram of UPQC during normal working condition}

The intermediate bus voltage $\mathrm{V}_{\mathrm{m} 1}$ is taken as the reference. The grid current $I_{S 1}$ is in anti-phase with the machine terminal voltage $\mathrm{V}_{\mathrm{L} 1}$, as there is no reactive power flow from the grid to the generator. The SHUC current $\mathrm{I}_{\mathrm{Cl}}$ is in quadrature to the machine terminal voltage as the SHUC current is purely reactive during normal operating condition.

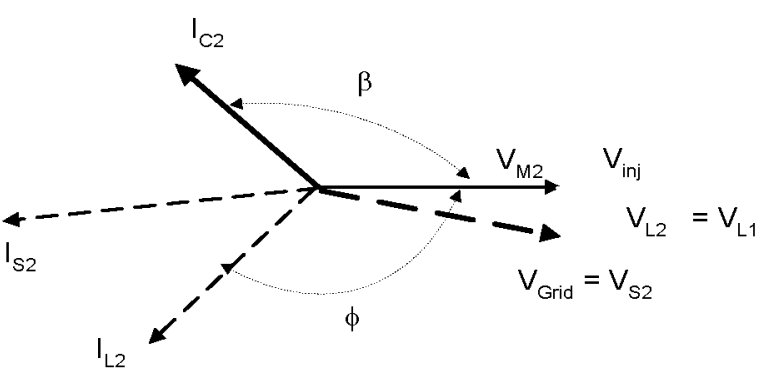

Figure 4. Phasor diagram of UPQC during fault 
During the fault condition the SHUC has to carry an extra component of current which is responsible for boosting up the voltage at the PCC through the SERC. The sharing of the real power is through the DC link capacitor. A power balance is maintained between the SHUC and the SERC such that the net active power generation or consumption by the UPQC is zero.

\section{Results}

The simulation and the analysis of the system shown in the Figure 1 was carried out in two steps. They are described in following sections

\subsection{Simulation Results without Capacitor}

A set of simulation studies were carried out on the system in the absence of the capacitor. A three-phase balanced fault is created at 2.5 second, which results in a $45 \%$ voltage sag at the PCC. The duration of the fault has been chosen to be 4 seconds, which is long enough to demonstrate the stable operation of the FSIG with UPQC in action. The shunt compensator of the UPQC caters for the reactive power requirement of the generator and the associated inductive devices. Figure 5 shows the reactive support given by the SHUC of the UPQC during the normal and the fault condition. The SERC of the UPQC compensates for the voltage sag such that the generator terminal voltage is maintained at a constant value. Figure 6 shows the different voltage levels.
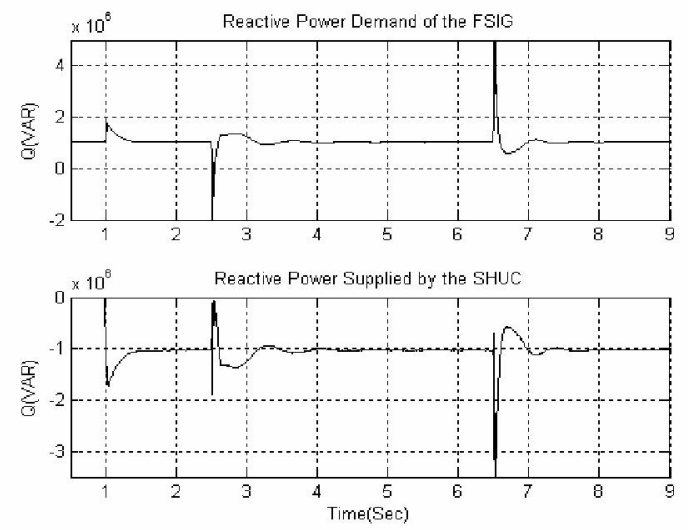

Figure 5. Reactive power demand of the machine and supplied by the SHUC

It was concluded in [2] that the capability of the FSIG to withstand the occurrence of a fault depends on maintaining the voltage at the PCC at a level such that power flow from the generator can be sustained and the reactive power demand of the machine is met.
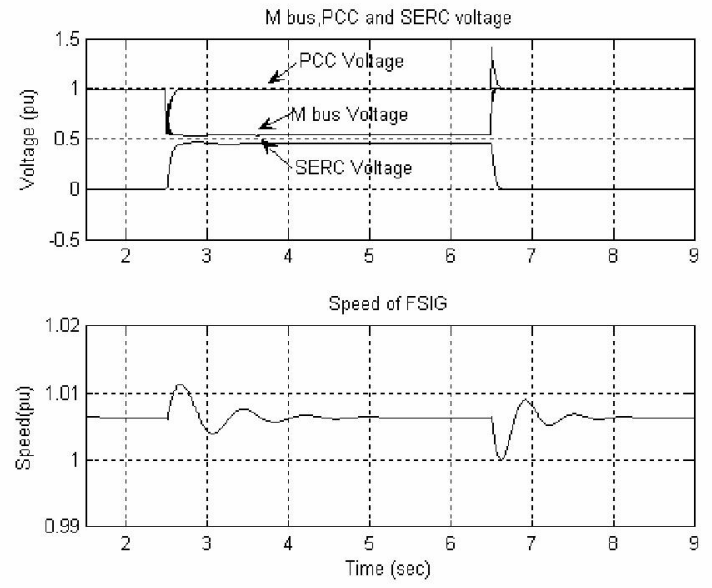

Figure 6. Voltage at PCC, intermediate bus and SERC

This implies that the terminal voltage of the machine need not be $100 \%$ compensated by the UPQC in order to achieve fault ride through. The rating of the individual compensators of the UPQC can be limited in order to minimise the rating of the UPQC. The simulation results shown in Figure 7 provide the proof for this concept. The machine does not over speed and the terminal voltage reaches its original value after the fault is cleared. Increased reactive power demand of the machine is met by the SHUC of the UPQC.

It was concluded in [2] that the rating of the UPQC to address a sag level depends on the depth, duration, location and the generator rating. The VA loading curves of the UPQC and the individual compensators to address a sag level of $45 \%$ have been presented in Figure 8. It was found from this curve that minimum rating of the UPQC yields the optimum rating of the individual compensators.
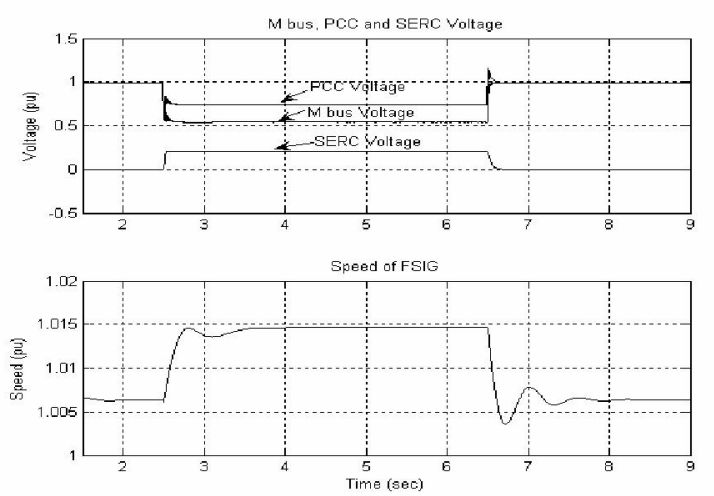

Figure 7. The voltage at the intermediate bus (M) and at the PCC, with $20 \%$ Compensation from the SERC of UPQC 


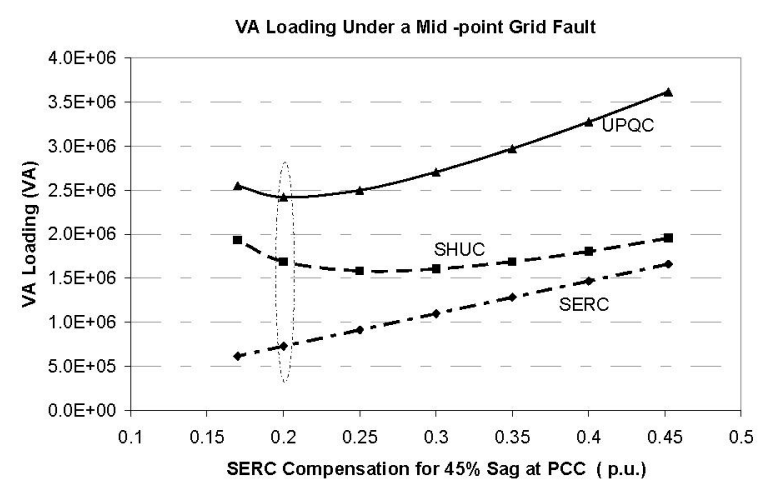

Figure 8. VA loading curve of the UPQC

\subsection{Simulation Results With Capacitor}

With a view to further reduce the rating of the UPQC, the same system was considered with a capacitor connected at the machine terminals at 3.5 second. The reactive power shared between the active and passive compensating device can be seen in ( Figure 9 ). $28 \%$ of the reactive power requirement of the generator is met by the capacitor. A balanced three phase fault is created at 5.5 second which is cleared after 3 seconds. The SERC of the UPQC comes in to action and compensates for the sag created. The reactive power requirement of the machine remains the same as the machine does not experience any voltage sag. The capacitor's ability to supply the reactive power also remains the same. The SHUC of the UPQC and the capacitor continues to share the reactive power in the same fashion during and after the sag period.
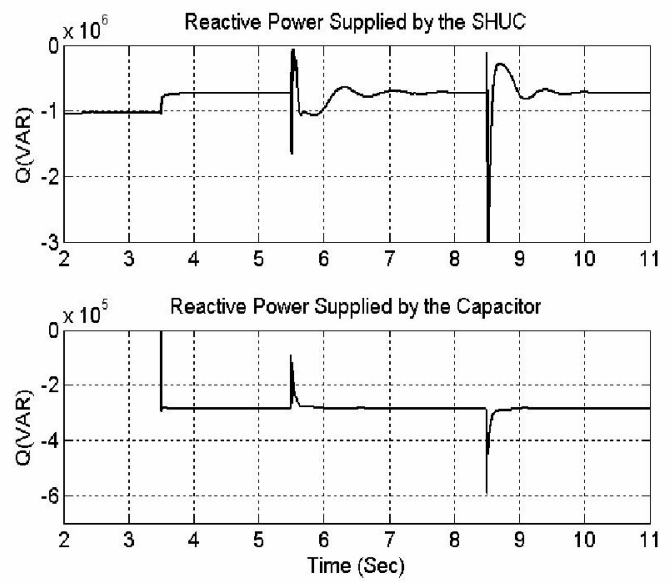

Figure 9. Reactive power sharing between the SHUC and the capacitor

In the next simulation study, the same fault situation was created. The rating of the individual compensators were selected on the basis of the general principle developed in [2], referring to the VA loading curves (Figure 8). 20\% voltage compensation is provided from the SERC, and the SHUC is over-rated to meet the increased reactive power demand. Figure 10 shows the reactive power sharing between the SHUC and the capacitor. A capacitor's ability to deliver the reactive power depends on its terminal voltage. Since the terminal voltage remains at $75 \%$ of its original value, capacitor's reactive power delivering ability is only $56 \%$ of the original value. In this situation the SHUC has to provide the extra reactive power required by the generator
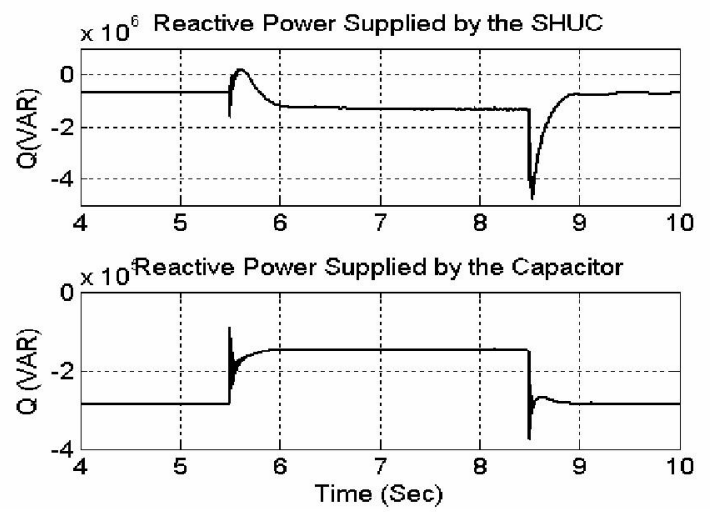

Figure 10. Reactive power sharing between the SHUC and the capacitor when UPQC rating is limited

\subsection{Optimised Rating of the UPQC}

The VA loading on the SERC and the SHUC of the UPQC in $100 \%$ voltage compensation case is found to be 1.66 MVA and 1.95 MVA respectively without a capacitor. By adopting the rating optimisation technique developed in [2] , the rating of the SERC and the SHUC are found to be 0.73 MVA and 1.69 MVA respectively. This reduces their rating by $56 \%$ and $13 \%$ respectively. As a further step of optimisation, the rating of the compensators in the presence of a fixed capacitor is calculated. They are found to be 0.73 MVA and 1.519 MVA for the SERC and the SHUC respectively. Application of the fixed capacitor which can deliver 0.29 MVAR of reactive power under normal working condition, which is $28 \%$ of overall reactive power requirement of the generator and associated inductive devices, reduces the rating of the SHUC by $9 \%$.

\section{Conclusions}

A UPQC is a potential solution to provide additional fault ride through capability to grid connected wind generators. The optimised rating of the UPQC can make this solution highly cost effective. The general principle developed in [2], and in this work together brings down the overall rating of the SHUC and the 
SERC by $22 \%$ and $56 \%$ respectively. The application of a fixed capacitance is very advantageous in reducing the rating of the SHUC of the UPQC. The on-state and the switching losses of the SHUC is also reduced because of the reduced current conduction in the presence of the capacitor. But the point to be noted here is that the ability of the capacitor to compensate for the reactive power reduces when it experiences a voltage sag at its terminals. The fast and the flexible nature of the SHUC of the UPQC can provide the deficit reactive power during such situations. A hybrid combination of the capacitor and the UPQC is found to be a more effective solution in terms of performance and cost.

\section{Acknowledgements}

The authors would like to acknowledge the support provided by Enterprise Ireland under the Technology Commercialisation Fund.

\section{References}

1. M. Basu, N. G. Jayanti, K. Gaughan, M. F. Conlon, "Application of a Unified Power Quality Conditioner (UPQC) to the enhancement of the fault ride-through capability of wind generation", $40^{\text {th }}$ University Power Engineering Conference (UPEC), 2005

2. N. G. Jayanti, M. Basu, Michael Conlon, Kevin Gaughan, "Rating Requirements of a UPQC for Voltage Ride Through Capability Enhancement", $3^{\text {rd }}$ IET International Conference on Power Electronics Machines and Drives (PEMD-06) Apr 2006, pp 632636.
3. T. Sun, Z. Chen, F. Blaabjerg, "Voltage recovery of grid-connected wind turbines after a short circuit fault", 29th Anmual Conference of the IEEE Vol. 3, pp 2723-2728, 2003

4. L. Holdsworth, X. G. Wu, J. B. Ekanayake and N. Jenkins, "Comparison of fixed speed and doubly-fed induction wind turbines during power system disturbances", IEE Proceedings-Generation Transmission and Distribution, Vol. 150, No. 3, pp 343-352, May 2003.

\author{
Appendix A \\ FSIG parameters (in pu) \\ Stator resistance $\left(R_{s}\right)=0.00488$ \\ Rotor resistance $\left(R_{r}\right)=0.00549$ \\ Stator reactance $\left(X_{l, s}\right)=0.09241$ \\ Rotor reactance $\left(X_{l r}\right)=0.09955$ \\ Magnetising reactance $\left(X_{m}\right)=3.95279$ \\ Lumped inertia constant $(H)=3.5 \mathrm{~s}$ \\ Base value considered are $V_{\text {base }}=690 \mathrm{~V}$, \\ $S_{\text {base }}=2 \mathrm{MW}$
}

\author{
AUTHOR'S ADDRESS \\ The first author can be contacted at \\ School of Control Systems and Electrical Engineering, \\ Dublin Institute of Technology, Kevin Street, Dublin 8, \\ Ireland. \\ Jayanti.navilgoneganesh@student.dit.ie
}

